Juliana Nichele ${ }^{1}$

Silvio Roberto Stefano ${ }^{2}$

Léo Raifur ${ }^{3}$

\title{
ANÁLISE DA REMUNERAÇÃO ESTRATÉGICA PARA ATRAIR E RETER COLABORADORES: A VISÃO DOS PÓS-GRADUANDOS
}

\section{Resumo}

O objetivo deste estudo consistiu em analisar como os profissionais são atraídos e retidos a partir da remuneração estratégica de acordo com a visão de alunos de Pós-Graduação de uma Universidade Pública. A metodologia utilizada nesse estudo foi realizada por meio de pesquisa de campo com uma amostra de 118 alunos. O conjunto inicial de 26 variáveis foi sintetizado, por meio da análise fatorial, em cinco fatores latentes: Plano de Carreira e Reconhecimento; Práticas de Gestão de Pessoas; Status no Trabalho e na Sociedade; Estabilidade e Flexibilidade, e; Salário. O estudo ainda constatou que o salário, condições de trabalho, qualidade de vida no trabalho, reconhecimento, valorização, benefícios, boa referência e comprometimento são aspectos que atraem talentos, enquanto salário, comprometimento, estabilidade e flexibilidade estimulam a permanência na organização.

Palavras-chave: Remuneração Estratégica. Salário. Atração e Retenção de Talentos.

\section{Abstract}

The purpose of this study was to examine how professionals are attracted and retained from the strategic remuneration according with the vision of students Postgraduate from a public university. The methodology used in this study was carried out through field research with a sample of 118 students of Post Graduate courses. The initial set of 26 variables was synthesized through of factor analysis, five latent factors: Career and Recognition; People Management Practices; Status at Work and Society; Stability and Flexibility, and; Wages. The study also found that the wages, working conditions, quality of work life, recognition, valuation, benefits, good reference and commitment are aspects that attract talent, while salaries, commitment, stability and flexibility stimulate stay in the organization. The salary was configured as the key aspect of attraction and retention.

\section{Keywords: Strategic Compensation. Wages. Attracting and Retaining Talented Professionals.}

1 MBA Gestão Estratégica de Pessoas pela Unicentro. (juliana_nichele@hotmail.com)

2 Pós-Doutor em Administração pela Univali. Doutor em Administração pela Universidade de São Paulo USP Faculdade de Economia, Administração e Contabilidade (2008), Mestrado em Administração pela PPGA UEM/UEL (2002). Atualmente é professor Adjunto da Universidade Estadual do Centro-Oeste UNICENTRO. Docente e Coordenador do Mestrado Profissional em Administração da Unicentro PPGADM. (professor-silvio@hotmail.com)

${ }^{3}$ Doutor em Administração pela FEA USP, Docente do PPGADM Unicentro (raifur@yahoo.com.br) 


\section{Introdução}

A Gestão de Pessoas nas organizações tem como foco principal os resultados através das pessoas, especificamente seus colaboradores, visto que o capital intelectual é o grande diferencial no mercado competitivo e não há duvidas que o seu sucesso dependa daqueles que a nela trabalham.

As empresas reconhecem que colaboradores satisfeitos são essenciais para o alcance de seus objetivos, mas nos dias atuais encontram dificuldades para manter um nível de motivação satisfatório. Neste sentido, observa-se que a motivação está relacionada com a maneira como os indivíduos recebem os estímulos externos, bem como do modo que suas necessidades são satisfeitas. Diante disso os gestores utilizam de diversos recursos buscando a satisfação e o comprometimento de seus funcionários (PASSOS, 2012, p.11).

Com o intuito de atrair e manter os profissionais qualificados do mercado, algumas organizações estão adotando a remuneração estratégica como forma de recompensas, buscando beneficiar o funcionário de forma mais adequada e satisfatória. Os benefícios sociais também estão sendo adotado na remuneração estratégica o que vêem complementar e agregar reconhecimento pelo trabalho oferecido à organização.

Os profissionais levam muito em consideração o salário em suas decisões, o grande desafio das empresas está em definir qual a remuneração é mais adequada seguindo a filosofia da organização e a que melhor se enquadra em seu quadro funcional, pois é um elo entre os dois interessados (TRINDADE, et al, 2011, p. 3).

Observa-se que diante do mercado atual as empresas estão à procura de profissionais qualificados e com talento, que possam trazer resultado para a organização. Na busca por esses talentos é imprescindíveis que as entidades obtenham boas estratégias na hora de realizar a gestão, para atrair os profissionais mais capacitados e mantê-los dentro da organização. De nada adianta também oferecer subsídios a fim de seduzir os talentos e não saber reter os grandes profissionais (NASCIMENTO, et al, 2011, p. 4).

Diante dessas considerações, esse trabalho se justifica pela dificuldade que as empresas encontram em atrair e manter profissionais qualificados, devido à grande concorrência existente pela busca de talentos, e enfatizando o diferencial que o capital humano é perante o mercado de trabalho.

Apoiando-se na importância estratégica que os colaboradores têm para uma organização, este estudo procurou responder a seguinte questão de pesquisa: Até que ponto a remuneração estratégica atrai e retém os profissionais nas organizações na visão de Pós-Graduandos? O objetivo principal deste estudo foi analisar como os profissionais das organizações são atraídos e retidos a partir da remuneração estratégica na visão de alunos de Pós-Graduação de uma Universidade Pública.

\section{Fundamentação Teórica}

O referencial teórico desta pesquisa abrange a apresentação: remuneração estratégica e atração e retenção de talentos. O referencial aqui abordado constitui como base para a análise dos dados e a solução do problema de pesquisa.

\subsection{Remuneração Estratégica}

A forma de pagamento fornecida aos funcionários passou por uma série de transformações no decorrer do tempo, antigamente era utilizada a remuneração tradicional, substituída pela estratégica, que busca oferecer um pagamento mais adequado e apropriado. A qual é utilizada muito nos dias de hoje. 
Segundo Chaguri (2000, p.12) citado por Silva (2006, p. 10) conceitua remuneração como:

O pagamento por um trabalho realizado, seja ele de nenhuma ou muita complexidade, eficiente ou não, normalmente acordado entre duas partes mediante um contrato tácito ou escrito. Uma remuneração tem como conotação ampla, podendo envolver formas de pagamentos diversas pelo trabalho desenvolvido. Salário, honorários, prêmios, Bônus, gratificações, adicionais, ajudas, horas extras, etc., são variáveis que comumente compõe uma remuneração de trabalho.

O que determina o trabalho assalariado é a remuneração, podendo definir como o pagamento pelo serviço prestado pelo funcionário, incluindo todas as formas de pagamento ou recompensa que a pessoa recebe pelo seu trabalho efetivado em prol da organização. Resumi-se basicamente em uma troca de contribuição para ambos.

As características da remuneração tradicional é ser mais burocrática, fortemente hierarquizada, possui um controle rígido, não acompanha as tendências nos modelos de gestão, bem como, demora na resolução dos problemas. Já partindo da remuneração estratégica o sistema adota uma remuneração que agrega valor aos funcionários, flexível, compreendida por variáveis, ágil na tomada de decisão, maior autonomia, níveis hierárquicos reduzidos, e leva em consideração as habilidades, competências e o desempenho dos profissionais (DIAS, BRITO, BRESSANE, 2010, p. 6).

Segundo Marquart, Lunkes, Rosa (2012, p.9) remuneração estratégia é definida como:

(..) uma combinação equilibrada de diferentes formas de remuneração, visando alinhar a remuneração à estratégia da organização, harmonizando interesses, ajudando a gerar consensos e atuando como meio de atingir os resultados esperados. Para alinhar a estratégia organizacional à remuneração, deve se vincular o resultado da empresa ao recebimento de determinados valores ou benefícios pelos empregadores.

A remuneração estratégica nos apresenta um ponto relevante, que não é fixar um salário a todos os funcionários de forma genérica, mas sim utilizar e atribuir métodos estratégicos e benéficos de retribuição para cada colaborador conforme sua contribuição à organização.

A adoção de um sistema de remuneração flexível parte de uma estratégia empresarial que visa tornar a empresa mais competitiva na busca por profissionais qualificados, adotando critérios como: criatividade, iniciativa, resultado e espírito empreendedor. Buscando um aumento na produtividade e satisfação de seus colaboradores (MARTINS, VERIANO, 2004, p. 26).

As estratégias das organizações devem estar alinhadas aos objetivos dos colaboradores e sua remuneração, uma vez que deve ser vista de forma sistêmica facilitando ao alcance de seus objetivos e não de forma isolada. Partindo da idéia de que os objetivos dos funcionários devem ser compatíveis com o da empresa, uma vez que um é atingindo conseqüentemente o outro também é, ou seja, um ganha o outro ganha.

O foco das organizações no quesito pagamento no momento atual é a remuneração estratégica, e isso se deve a observação dos gestores em que o sucesso de qualquer estratégia de Recursos Humanos deve agregar valor aqueles que acabam por contribuir e gerar resultados positivos (ZAMBRANO, MERINO, CASTELLANOS, 2012, p. 18).

A remuneração não passa de uma estratégica utilizada a fim de tentar motivar seus talentos, mas vale ressaltar que segundo Berganini (1997, p. 82) "ninguém motiva ninguém", a motivação vai depender do significado que cada ser atribui aos artifícios utilizados. A motivação esta atrelada as condições que os gestores proporcionam aos funcionários, para o alcance de suas necessidades e expectativas. 
A remuneração básica é o principal componente da remuneração total que é o pagamento fixo. Mas os componentes de incentivos salariais e os benefícios são os diferenciais e vantagens concedidas que agregam valor a remuneração, contribuindo para que tal empresa mantenha-se em destaque frente aos profissionais.

Pode-se dizer que a remuneração estratégica é divida em duas partes: fixa e variável. No item fixo considera-se a: remuneração funcional, habilidades, competência, salário indireto. Já a parte variável vai depende do desempenho individual, da participação acionária, a relação com os objetivos da organização e sua lucratividade, alternativas que incluem prêmios, entre outras formas especiais de reconhecimento (NASCIMENTO,2001 apud GHENO, BERLITZ, 2011, p. 271).

Remuneração funcional, ou seja, tradicional é fixada pela função exercida seguindo o Plano de Cargos e Salários, e seu ajuste é conforme o mercado de trabalho. Seu foco é o cargo e não o indivíduo. Seria o tratamento de coisas diferentes de forma homogênea, não olhando os conhecimentos individuais.

Na remuneração por habilidades o enfoque principal é o funcionário, o que determina a base da remuneração são as habilidades que o indivíduo desenvolverá e não pela sua função ou cargo. A tendência é que o indivíduo evolua profissionalmente tornando-se responsável pelo seu desenvolvimento, com base nessa intenção as entidades estão usando a remuneração como uma forma de ligação a esse desenvolvimento, servindo como um estimulo a essa evolução. Diferente da remuneração por habilidades que é aplicada no nível operacional, a por competência é mais interessante para os demais níveis da organização e envolve muito o comportamento individual para o alcance de metas. A remuneração por habilidade abrange a parte técnica e operacional já a por competência a área administrativa. (WOOD e PICARELI FILHO, 2004 citado por DIAS, BRITO, BRESSANE, 2010, p.7)

O salário indireto envolve os benefícios e outras vantagens concedidas pelas entidades, aonde na forma tradicional os benefícios variam de acordo com os níveis hierárquicos e na forma flexível o funcionário define seu pacote de benefícios. As organizações passaram a utilizar os planos flexíveis, concedendo aos beneficiários o direito de escolher os benefícios fornecidos que condiz e irá atender melhor as suas reais necessidades, conforme o perfil de cada um. (WOOD e PICARELI FILHO, 2004 citado por DIAS, BRITO, BRESSANE, 2010, p.7)

A remuneração variável está relacionada ao cumprimento de metas pré-estabelecidas relacionando o desempenho individual, da equipe e da organização. A participação acionária está inclusa com objetivos de lucratividade e compromissos a longo prazo, utilizando a participação dos lucros, remuneração por resultados e participação acionária. Outro método utilizado na remuneração variável são as chamadas alternativas criativas que incluem as formas de reconhecimento como prêmios e gratificações. (WOOD e PICARELI FILHO, 2004 citado por DIAS, BRITO, BRESSANE, 2010, p.7).

Segundo Marras (2002, p. 177) apud Gheno e Berlitz (2011, p. 274) "A participação nos lucros trata de um sistema que permite contemplar com uma parcela em espécie a todos os funcionários da empresa, em função dos dados da lucratividade levantada pela empresa no fim de determinado período". Este tipo de programa buscar entrelaçar os objetivos de cada departamento com os definidos pela organização.

A remuneração por resultados é uma das formas mais praticadas, esta diretamente ligada ao desempenho do funcionário á produtividade, aonde são atribuídos metas, indicadores e objetivos, focando no trabalho e alcance dos resultados de forma coletiva. A participação acionária consiste em distribuir ações da organização para os colaboradores, é um método de remuneração que premia o desempenho e os resultados. Esse tipo de remuneração tende a aumentar o comprometimento dos funcionários, uma vez, que eles passam a se sentir parte e proprietários (GHENO e BERLITZ, 2011, p.275). 
Em termos de estratégias de compensação ressalta-se que é importante a empresa atribuir estratégia de recompensa de forma diferenciada conforme a evolução de sua contribuição: fase inicial, fase de crescimento, posição de maturidade. Conforme o estágio em que o funcionário se encontra as práticas de envolvimento e reconhecimentos.

Para Ciavarella (2003) citado por Wang e Singh (2013, p. 147) define uma forma de reconhecimentos para os estágios citados anteriormente.

As empresas utilizam o reconhecimento ou orientado para o futuro recompensas em fase de introdução, compartilhamento de ganho e de participação nos lucros na fase de crescimento, planos de compra de ações a empregados no estágio de maturidade, e uma retirada de sistemas de recompensa para conservar os recursos na revitalização e / ou estágio de declínio.

Vale ressaltar que a empresas precisão ter flexibilidade e estratégica para avaliar e definir qual é o melhor método de remunerar seu corpo funcional, a fim de atribuir valor e reconhecimento aos serviços prestados, com o objetivo de satisfazer os profissionais e assim conseguir atrair-los e reter-los na organização.

\subsection{Atração e Retenção de Talentos}

As transformações no mercado de trabalho nos últimos anos submeteram as empresas a uma série de mudanças, principalmente na sua forma de gestão. Pautando em um novo modo de gerir o seu capital intelectual, investindo na flexibilidade, inovação, conhecimento e excelência.

Partindo dessas mudanças, as organizações se depararam com uma série de dificuldades, entre as quais, a escassez da mão-de-obra especializada. Consequentemente em decorrência dessa falta de qualificação, a concorrência entre as empresas em atrair e reter os profissionais talentos aumentou (DUNZER, MELO, MELO, 2008, p. 2).

Muitas entidades ainda não perceberam que o foco do mercado atual é investir em seus ativos intangíveis, nas pessoas. O enfoque deixou de ser o maquinário e passou a ser o ser humano. Diante dessa situação faz-se necessário olhar o colaborador com outros olhos, não o de como se ele fosse uma despesa, mas sim um investimento (JUNIOR, 2010, p.32).

Pode-se dizer que o grande desafio é encontrar meios que seduzem e convençam os profissionais do mercado a optar e permanecer dentro da sua empresa. Por esse motivo os gestores estão investindo e reconhecendo o trabalho dos indivíduos, uma vez, que nos dias de hoje o capital humano é o grande diferencial. Tecnologias, equipamentos, maquinários, treinamentos e etc, podem em alguns casos serem os mesmos ou copiados de outra entidade, mas o talento do corpo funcional de uma organização nunca será o mesmo que o da outra, é a grande vantagem competitiva do mercado.

Diante dessa importância do ser humano perante as entidades, é indispensável à gestão de talentos. Porque ter pessoas trabalhando não significa que se possuem pessoas talentosas, existe uma grande diferencia entre um funcionário e um funcionário talento.

Segundo Michaels, Handfield e Axerold (2002) apud Silva (2006, p.21), talento pode ser definido como "conjunto de habilidades de uma pessoa. Os dons, conhecimento, experiência, inteligência, discernimento, atitude, caráter e impulsos inatos, e que inclui ainda a capacidade de aprender".

Os talentos são identificados perante os outros, pois se destacam, estão em constante aperfeiçoamento, tem senso de responsabilidade, possuem conhecimentos, técnicas, são inovadores, eficientes, eficazes, exercem sua função muito além do que ela exige, realizam com a cabeça e o coração. Os talentosos possuem habilidades de fazer melhor do que os 
demais. O talento pode ser desenvolvido, não é algo em que se nasce, mas sim se adquire. (JUNIOR, 2010, p.32).

A palavra atrair rege basicamente sobre dois termos: encantar e seduzir. Para atrair o bom profissional devesse deixar explícito tudo que a empresa irá fornecer e conceder ao candidato, por sua vez ele já identifica que atributos ele considerar positivo, o que em algum caso acaba por seduzi-lo. (MELO, SANTOS, 2012, p. 3).

Já a retenção é vista como a habilidade da organização em cultivar o indivíduo, é manter os funcionários essenciais. As práticas de retenção estão associadas à gestão de talentos, é a maneira como se deve investir em recursos financeiros e humanos que fazem com que o colaborador permaneça na empresa (MELO, SANTOS, 2012, p. 3).

As empresas não estão em busca apenas de indivíduos para compor sua equipe, mas sim de pessoas que irão agregar valor a ela e contribuem de forma significativa para o seu sucesso. As companhias identificam quais as competências que consideram relevantes com base em sua cultura organizacional, nesse levantamento identificam característica para seduzir-los e mante-los. Vale ressaltar que não adianta iludir os profissionais com promessas falsas, pois implicar apenas em um gasto pra empresa, uma vez que realizará uma contratação errada.

O grande motivo que faz com que um profissional seja atraído e retidos são atributos que aumentem a sua motivação e está atrelada a cultura organizacional. Conforme Maximiano (2000) citado por Miranda (2009, p.11) "a palavra motivação indica o processo pelo qual um conjunto de razões ou motivos explica, induz, incentiva, estimula ou provoca algum tipo de ação ou comportamento humano". São artifícios que vão fazer com que o indivíduo aja de forma satisfatória.

A competitividade no mercado exige que as organizações conheçam os perfis dos seus profissionais para que possam assim alinhar as suas expectativas individuais aos valores, missão e estratégicas organizacionais. Objetivando que o perfil e o estágio da vida profissional influenciam na motivação do indivíduo.

Para motivar seus colaboradores as empresas precisam de algo além que remuneração. Neste sentido, Leonardo (2002) citado por Melo e Santos (2012, p.3) "que a área de recursos humanos assuma diferentes medidas para a manutenção dos talentos da empresa. De modo geral, essas medidas estão relacionadas tanto a aspectos materiais (por exemplo, salário), como a aspectos sociais do trabalho (por exemplo, estilo de liderança)."

Para Hausknecht, Rodda e Howard (2009) citado por Melo e Santos (2012, p.3) estabeleceram 12 fatores que contribuem para a retenção de funcionários:

Satisfação com o trabalho; Falta de alternativas; Recompensas extrínsecas; Oportunidades de desenvolvimento; Fator relacional; Investimento; Influências não relacionadas ao trabalho; Comprometimento organizacional; Justiça organizacional; Prestígio organizacional; Plano de flexibilidade no trabalho; e, Localização.

São fatores que acabam por motivar o funcionário e quanto mais motivados os maiores são as chances de ele permanecer na empresa, porque ele encontra-se satisfeito com o que ela tem a lhe oferecer momentaneamente. O reconhecimento e a compensação aos funcionários desempenham um papel importante no quesito de incentivar e enfatizar o comportamento dos mesmos (WANG, SINGH, 2013, p.148).

As técnicas de gestão do capital humano estão voltadas a atrair e reter talentos e fundamentadas em um pacote de atributos, são eles: recrutamento e seleção, desenvolvimento pessoal e de carreira, planos de cargos e salários, qualidade de vida, remuneração estratégica, estilo de gestão e etc. Isto é, perspectivas que levam as pessoas a se desenvolverem e sentirem motivadas, para isso as empresas desenvolvem estratégias com esse objetivo (JUNIOR, 2010, p.33-34). 
Um fator utilizado como estratégia para atrair e reter talentos é oferecer ao seu corpo funcional a oportunidade de desenvolvimento. Nenhum funcionário talento deseja se manter estável, desenvolvendo a mesma função, no mesmo cargo e recebendo o mesmo salário, estabilidade, bem como possui as mesmas habilidades, competências e conhecimentos, por um longo período de tempo. Os talentos buscam inovação e aprendizagem. (JUNIOR, 2010, p.31).

Pode-se ressaltar que o clima organizacional possui grande influencia no comportamento das pessoas e na sua percepção, e os funcionários estão cada vez mais envolvidos com empresas que apresentam esses efeitos. O grande problema na questão de retenção está em criar um ambiente em que o colaborador deseje permanecer, que é: aonde ele encontre um ambiente harmonioso e motivador, que possa se desenvolver constantemente e sinta-se valorizado (ZHANG, WANG, ZHOU, 2013, p. 282). Os profissionais desejam fazer o que gostam e atuar com autonomia em entidades que contribuem e proporcionem seu desenvolvimento.

Com base nesta abordagem pode-se dizer que ao valorizar o colaborador de forma ampla e utilizar estratégias, conforme atributos aqui já mencionados, a companhia cultiva e atrai seus talentos, partindo desse reconhecimento os mesmos vão querer permanecer e contribuir para o desenvolvimento da empresa.

\section{Metodologia de Pesquisa}

A metodologia do estudo envolveu a pesquisa bibliográfica, realizando um levantamento sobre algumas publicações sobre o assunto. Sendo feito também uma pesquisa de forma exploratória, uma vez que se busca adquirir conhecimento aprofundado do tema em questão, que segundo Gil (2002, p. 41), "a etapa de pesquisa exploratória tem como objetivo proporcionar maior familiaridade com o problema, tornando-o mais explícito, ao envolver um levantamento bibliográfico e entrevistas com pessoas que tiveram experiência prática com o problema pesquisado".

Foi realizada uma pesquisa aplicada com o intuito de demonstrar como é levado em consideração o fator remuneração na atração e retenção de talentos. A pesquisa é descritiva, o que exige do pesquisador um grande número de informações sobre o que deseja pesquisar. Esse tipo de estudo pretende descrever os fatos e fenômenos de determinada realidade (GERHARDT e SILVEIRA, 2009 citado por TRIVIÑOS, 1987).

Quanto à classificação da metodologia é quantitativa, o que aborda a formulação de hipóteses operacionais das variáveis, quantificação das coletas de dados e informações obtidas aplicadas a tratamentos estatísticos (GRESSLER, 2004).

Para um melhor entendimento e apresentação dos dados obtidos na pesquisa, foi utilizado para demonstrar os resultados porcentagem, porcentagem cumulativa, média, correlação spearman e fatorial, para uma melhor observância e análise.

AAnálise Fatorial foi utilizada devido ao grande número de variáveis, e tem como objetivo encontrar um método que resume as informações contidas nas diversas variáveis em um conjunto menor, com uma perda mínima de informações (HAIR, 2005, p. 94).

O pressuposto comunalidade apresenta segundo Hair (2005, p. 90) a "quantia total de variância que uma variável original compartilha com todas as outras variáveis incluídas na análise", variáveis menores que 0,5 não é captada e sim classificada como não tendo explicação suficiente. O método VARIMAX simplifica as colunas da matriz fatorial e maximiza a soma das variâncias exigidas, apresentando de forma mais clara a separação dos fatores, o experimento KAISER indica através da VARIMAX o padrão fatorial obtido mais invariante (HAIR, 2005, p. 106). A seguir apresenta-se as análises de dados e resultados da pesquisa de campo. 


\section{Análise de dados e Resultados}

Neste tópico serão apresentados e abordados os resultados obtidos na pesquisa, a qual foi aplicada a 118 estudantes de pós-graduação do setor de Ciências Sociais Aplicada de uma Universidade Pública do Paraná, atuantes em diversas áreas e empresas. Para iniciar a análise dos dados, primeiramente apresenta-se uma busca pelo perfil dos entrevistados, como idade, gênero e cargos desempenhados.

Com base na pesquisa realizada, a faixa etária que abrange maior atuação é entre 18 a 33 anos, as quais tiveram um percentual acumulativa de $78,8 \%$, aonde a relação entre 18 a 25 anos e de 26 a 33 anos são muito próximas. A faixa etária acima de 42 anos é considerada pequena relacionado a os outros índices, com apenas 2 dos 118 entrevistados.

Tabela 1 - Perfil Cargos X Idade

\begin{tabular}{|c|c|c|c|}
\hline \multirow{2}{*}{ Cargo } & \multicolumn{2}{|c|}{ Gênero } & \multirow{2}{*}{ TOTAL } \\
\hline & Masculino & Feminino & \\
\hline Gerência & 36 & 19 & 55 \\
\hline Técnico & 14 & 20 & 34 \\
\hline Operacional & 13 & 16 & 29 \\
\hline TOTAL & 63 & 55 & 118 \\
\hline
\end{tabular}

A Tabela 1 mostra que o sexo masculino apresenta-se de forma relevante no cargo gerencial e as mulheres atuam quase de forma homogênea em todos os níveis hierárquicos, com maior frequência na área técnica.

Em relação ao perfil dos respondentes da pesquisa o cargo de gerência possui atuação de $46,6 \%$, seguida de nível técnico com $28,8 \%$ e na área operacional com $24,6 \%$, esse índice apresenta-se de forma significativa pela formação de pós-graduandos dos pesquisados. Outro resultado encontrado foi que $53,4 \%$ são homens, e $46,6 \%$ são do gênero feminino.

Tabela 2 - Perfil de salário por tempo de atuação

\begin{tabular}{|c|c|c|c|c|c|}
\hline \multirow{2}{*}{ Salário } & \multicolumn{4}{|c|}{ Tempo } & \multirow{2}{*}{ TOTAL } \\
\hline & 0 a 3 anos & 4 a 7 anos & 8 a 11 anos & Acima de 11 anos & \\
\hline Até $1.448,00$ & 20 & 3 & 1 & 0 & 24 \\
\hline $1.448,01$ até $2.172,00$ & 18 & 9 & 1 & 1 & 29 \\
\hline $2.172,01$ até $2.896,00$ & 6 & 7 & 0 & 1 & 14 \\
\hline $2.896,01$ até $3.620,00$ & 5 & 8 & 1 & 3 & 17 \\
\hline $3.620,01$ até $4.344,00$ & 5 & 6 & 1 & 0 & 12 \\
\hline Acima de $4.344,00$ & 7 & 9 & 3 & 3 & 22 \\
\hline Total & 61 & 42 & 7 & 8 & 118 \\
\hline
\end{tabular}

O tempo de permanência dos funcionários dentro de uma organização correspondente as respostas obtidas na pesquisa, o período de até 3 anos de atuação é de $51,7 \%$, de 4 a 7 anos o índice é $35,6 \%$. Nota-se através dos dados que existe uma rotatividade significativa, esse fato pode justificar-se pela falta de estratégias para reter os profissionais nas empresas. 
Conforme a análise da pesquisa pode-se dizer que os salários que mais compõem a remuneração dos colaboradores são até $\mathrm{R} \$ 2.172,00$ com um índice acumulativo de 44,9\%, $79,66 \%$ recebem acima de $R \$ 1.448,01$. O valor dos salários pagos é variado, visto que os entrevistados atuam em cargos e tempo de atuação diferenciada. Segundo o Cadastro Geral de Empregados e Desempregados a média salarial do Brasil em 2013 foi de $R \$ 1.104,12$, observa-se o que o salário dos entrevistados encontra-se acima da média nacional.

Para uma melhor observação e análise foi cruzado o tempo de atuação com o salário recebido, que pode justificar os salários recebidos. Com base na Tabela 2 identifica-se que 61 dos entrevistados atuam até 3 anos na organização, seguido de 42 de exercem suas funções de 4 a 7 anos, 7 estudantes que trabalham de 8 a 11 anos na empresa e 8 que estão agindo acima de 11 anos. Temos que conforme o tempo de permanência na empresa a remuneração aumenta gradativamente, na maioria dos casos.

Tabela 3 - Retenção de Talentos

\begin{tabular}{|c|c|c|c|c|c|c|}
\hline Requisitos & 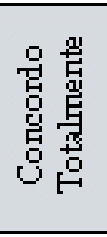 & 莺 & 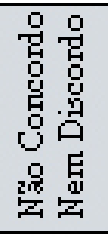 & 昫 & 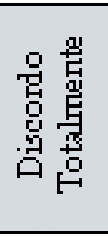 & 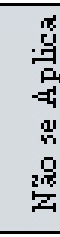 \\
\hline As pessoas são o foco principal de uma organização & 32 & 43 & 12 & 11 & 1 & 1 \\
\hline Você é (se considera) um talento dentro da empresa & 17 & 56 & 21 & 4 & 2 & - \\
\hline $\begin{array}{l}\text { A organização que trabalha oferece vantagens para reter seus talentos } \\
\text { (permanecer na empresa porum deteminado periodo), prevenindo } \\
\text { assim o risco de perda desse talento para outra grganizacá }\end{array}$ & 13 & 43 & 19 & 15 & 2 & 8. \\
\hline $\begin{array}{l}\text { O aspecto salarial é o maior fator de atração e retenção de talentos na } \\
\text { organização }\end{array}$ & 18 & 30 & 28 & 20 & 3 & 1 \\
\hline $\begin{array}{l}\text { Em temos de política de atração e retenção de talentos na } \\
\text { organização, um pacote de vantagens é melhor que um salário maior. }\end{array}$ & 9 & 39 & 35 & 12 & 2 & 3 \\
\hline Já me senti atraido a ir para outra organização por causa do salário & 20 & 47 & 17 & 10 & 4 & 2 \\
\hline
\end{tabular}

(*) Os valores da Tabela estão apresentados na forma porcentual e média.

A Tabela 3 evidencia que $75 \%$ afirmam que as pessoas são o foco principal em uma organização o que nos apresenta uma média mais elevada comparada aos outros itens de 2,4 , os demais não relacionam o capital intelectual como fator principal. Quanto às habilidades de um profissional $73 \%$ consideram-se um talento para a empresa, $27 \%$ asseguram não ter capacidade de exercem sua função muito além do que ela exige.

Com o intuito de reter talentos $56 \%$ confirmam que as empresas se preocupam com seus profissionais qualificados permaneçam na empresa, proporcionando algumas vantagens a eles, $45 \%$ relatam que a organização não apresenta um pacote de benefícios para prevenir o risco de perdas para outra.

Quanto à remuneração, a Tabela 3 apresenta que $48 \%$ dos pesquisados concordam que este aspecto é o maior fator de atração e retenção de talentos nas organizações. Observar-se que $52 \%$, aproximadamente metade dos pesquisados, não levam de forma expressiva o fator remuneração com o principal fator para se sentir atraído e permanecer na empresa.

Referente à relação de pacote de vantagem e salário, verifica-se que $52 \%$ das respostas não vêem um pacote de vantagens como requisito fundamental. Esse fato pode-se justificar que a empresa oferece benefícios que não condiz com o perfil do funcionário, ou seja, benefícios proporcionados e que nem todos iram usufruir, preferindo assim um salário maior. 
Dos entrevistados $48 \%$ consideram que os benefícios agregam mais valor que o salário em sim. A média de 1,5 também explica que os benefícios nem sempre são melhores que um salário maior visto que a foram apontados com pouca relevância pelos trabalhadores.

Ainda, segundo a Tabela 3 um número expressivo de $67 \%$ já se sentiu atraídos a mudar de organização pelo fator salário. Pode-se notar que 33\% não avaliam este quesito tão relevante, conforme apresentado nas outras opções de respostas.

Tabela 4 - Reconhecimento e valorização

\begin{tabular}{|c|c|c|c|c|c|c|c|c|c|c|c|}
\hline \multicolumn{12}{|c|}{$\begin{array}{l}\text { Como você avalia a importância do fator "reconhecimento e valorização dos } \\
\text { colaboradores", no ambiente de traballho (atribua uma nota de } 1 \text { a 10). }\end{array}$} \\
\hline Hada & 1 & 2 & 3 & 4 & 5 & 6 & 7 & 8 & 2 & 10 & \multirow{2}{*}{$\begin{array}{l}\text { Muito } \\
\text { Importante }\end{array}$} \\
\hline Importante & - & - & 1 & - & 2 & - & 6 & 19 & 17 & 55 & \\
\hline
\end{tabular}

Obs.: Valores em percentual

Verificam-se na Tabela 4 que a valorização e reconhecimento dentro de uma organização são fatores importantes com $97 \%$, o que mostra que os funcionários levam em consideração o tratamento e a preocupação que as empresas possuem com o seu corpo funcional. Os indivíduos em situações de trabalho são motivados pela necessidade de ser valorizadas e ser reconhecidas pelas suas realizações, é uma força propulsora que os eleva a satisfação (BERGAMINI, 2008 apud MIRANDA, 2009, p.59).

Tabela 5 - Fatores que levaram a escolher a empresa em que você trabalha.

\begin{tabular}{lccccccc}
\hline & \multicolumn{3}{c}{ Nada importante } & & \multicolumn{3}{c}{ Muito importante } \\
\cline { 2 - 8 } Fator & $\mathbf{1}$ & $\mathbf{2}$ & $\mathbf{3}$ & $\mathbf{4}$ & $\mathbf{5}$ & $\mathbf{6}$ & $\mathbf{7}$ \\
\hline Ambiente de trabalho & 4 & 3 & 3 & 11 & 31 & 29 & 37 \\
Salário & 1 & 1 & 5 & 15 & 28 & 33 & 35 \\
Comprometimento com o trabalho & 1 & 3 & 2 & 15 & 38 & 37 & 22 \\
Boa referência na sociedade & 2 & 4 & 8 & 9 & 23 & 39 & 33 \\
Beneficios & 8 & 5 & 4 & 15 & 23 & 26 & 37 \\
Reconhecimento & 5 & 3 & 7 & 15 & 19 & 32 & 37 \\
Novos desafios & 6 & 3 & 8 & 10 & 19 & 26 & 46 \\
\hline
\end{tabular}

Obs.: Valores em percentual

Quando perguntados sobre os fatores que levaram a escolher a empresa que trabalha atualmente, a respeito dos itens descritos na Tabela 5, os resultados apontados são: todos os quesitos são levados em consideração no momento de optar pela empresa em que se trabalhar, no entanto, salário apresentou a maior média com 5,6, o ambiente de trabalho, boa referência da organização na sociedade e novos desafios apresentaram uma média de 5,5 , com essas médias de abordagem analisamos que são fatores avaliados com rigor pelos funcionários; os benefícios oferecidos e o reconhecimento aparecem com freqüência menor que 90 , no intervalo de importância de 5 a 7 , sendo considerados menos influenciáveis que os demais. 
Tabela 6 - Razões que fazem com que você continue trabalhando nessa empresa.

\begin{tabular}{lccccccc}
\hline \multirow{2}{*}{ Fator } & \multicolumn{3}{c}{ Nada Importante } & \multicolumn{4}{c}{ Muito Importante } \\
\cline { 2 - 8 } & 1 & 2 & 3 & 4 & 5 & 6 & 7 \\
\hline a) Oportunidade de desenvolvimento & 4 & 2 & 2 & 12 & 20 & 24 & 36 \\
b) Salário & 1 & 1 & 4 & 11 & 18 & 34 & 31 \\
c) Comprometimento como Trabalho & 1 & 3 & 3 & 10 & 22 & 22 & 39 \\
d) Boa Referência na Sociedade & 3 & 2 & 7 & 12 & 21 & 32 & 23 \\
e) Beneficios & 5 & 3 & 8 & 10 & 22 & 26 & 25 \\
f) Reconhecimento & 5 & 3 & 5 & 9 & 16 & 33 & 28 \\
g) Novos Desafios & 3 & 2 & 6 & 13 & 23 & 24 & 30 \\
h) Plano de cargos & 12 & 3 & 5 & 16 & 18 & 22 & 24 \\
i) Clima organizacional & 6 & 3 & 4 & 16 & 16 & 28 & 26 \\
j) Estabilidade e segurança & 3 & 5 & 4 & 15 & 17 & 20 & 35 \\
k) Satisfação como trabalho & 3 & 3 & 3 & 15 & 18 & 22 & 36 \\
l) Flexibilidade no trabalho & 3 & 3 & 8 & 12 & 21 & 24 & 31 \\
m) Falta de altemativas & 33 & 2 & 7 & 19 & 9 & 10 & 16 \\
\hline
\end{tabular}

Obs.: Valores em percentual e média.

Na Tabela 6 evidenciam-se as razões que fazem com que os entrevistados permaneçam nas empresas em que atuam no momento. A oportunidade de desenvolvimento, salário e comprometimento com o trabalho são atribuídos como componentes fundamentais em grau de importância; a boa referência na sociedade, benefícios, reconhecimento, novos desafios, plano de cargos, clima organizacional, estabilidade e segurança, satisfação com o trabalho e flexibilidade de horários também se apresentam como itens básicos para continuarem na empresa. Ainda, de acordo com dados, a falta de alternativas aparece com $35 \%$ no intervalo de importância de 5 a 7.

Tabela 7 - Práticas de Gestão de Pessoas

\begin{tabular}{lcccccccc}
\hline & \multicolumn{3}{c}{ Classificação } & Nada Importante & \multicolumn{3}{c}{ Muito Importante } \\
\cline { 2 - 9 } & $\mathbf{1}$ & $\mathbf{2}$ & $\mathbf{3}$ & $\mathbf{4}$ & $\mathbf{5}$ & $\mathbf{6}$ & $\mathbf{7}$ \\
\hline a) Política de Beneficios e Incentivos & 3 & 3 & 4 & 5 & 19 & 25 & 36 \\
b) Salário & 1 & 2 & 3 & 5 & 23 & 31 & 31 \\
c) Reconhecimento e Valorização no Trabalho & 2 & 2 & 1 & 8 & 15 & 28 & 39 \\
d).Programas de Qualidade de Vida no Trabalho & 2 & 2 & 5 & 11 & 11 & 28 & 23 \\
e) Oporturidade de desenvolvimento & 2 & 1 & 3 & 9 & 14 & 28 & 25 \\
f) Condiçón de Trabalho & 2 & 1 & 3 & 8 & 13 & 27 & 28 \\
\hline
\end{tabular}

Obs.: Valores em percentual e média.

Segundo Tabela 7 observa-se que dentre as práticas abordadas no questionário para classificação referente aos métodos de Gestão de Pessoas, todas obtiveram um percentual considerado alto quanto ao seu grau de importância, isto é, os entrevistados consideram importantes esses meios de gestão e que deveriam ser utilizados para atrair e reter os talentos na organização. Analisando a média isoladamente verifica-se que os programas de qualidade de vida no trabalho ainda são vistos com receio pelos trabalhadores, com um número de 3,8. Já o reconhecimento e o salário aparecem com média de 4,7 sendo apontados com maior nível de importância na pratica da Gestão de Pessoas. 
Tabela 8 - Remuneração Estratégica

\begin{tabular}{lc}
\hline Cargo & Porcentagem \\
\hline Rernmeração funcional(Plano de carzos e salários). & 48 \\
Rerrumeração variável(remuneração por resultados, participação nos hacros etc). & 35 \\
Rernmeração por competências (área administrativa) & 26 \\
Salánio indireto (beneficios oferecidos) & 12 \\
Rerrumeração por habilidade (parte técrica e operacional) & 8 \\
Participação acionária. & 4 \\
H válido (de lista) & 0 \\
\hline
\end{tabular}

Os dados da Tabela 8 mostram que método de remuneração utilizado com maior vigor pelas empresas em que os entrevistados trabalham é a remuneração funcional, com $48 \%$, na qual se possui um plano de cargos e salários, ou seja, conforme o cargo de atuação do funcionário, as atividades e o salário será diferenciado. Seguido da remuneração variável, a qual varia conforme o resultado e o lucro da empresa, onde os profissionais recebem uma participação; e remuneração por competências, mais aplicada a área administrativa.

O tipo de remuneração por participação acionário é utilizada por 5 entre os 118 funcionários pesquisados. O método de remuneração menos aplicado dentre os entrevistados é a participação acionária, ou seja, conforme o desempenho do colaborador ele acaba por adquirir ações da empresa, o que lhe faz torna-se dono da empresa em que trabalha.

Tabela 9 - Benefícios Percebidos

\begin{tabular}{lc}
\hline Beneficios & Porcentagem \\
\hline Assistência médica & 47 \\
Vale alimentação & 43 \\
Seguro de vida & 36 \\
Assistência odontológica & 32 \\
Plano de previdência & 31 \\
Vale transporte & 29 \\
Refeitónio & 20 \\
Auxilio doença & 14 \\
Auxilio educação & 10 \\
Assistência financeira & 9 \\
Auxilio creche & 8
\end{tabular}

No que diz respeito aos benefícios que as empresas concedem aos seus funcionários, os respondentes poderiam assinalar mais que uma opção, como evidencia a Tabela 9. De acordo os dados obtidos mediante pesquisa têm que assistência médica e vale alimentação são benefícios que mais são proporcionados. Essa diferença significativa em relação aos demais benefícios deve-se a valorização com a saúde e a qualidade de vida dos funcionários, e também quanto ao alcance das necessidades básicas dos indivíduos. O seguro de vida, assistência odontológica e plano de previdência, também são utilizados com freqüência. $O$ benefício menos abordado e utilizado é o auxílio creche, justamento pelo fato de não beneficiar todos os colaboradores da organização. 
Tabela 10 - Sugestão de atração e retenção dos colaboradores

\begin{tabular}{lc}
\hline Sugestão & Porcentagem \\
\hline Clima organizacional & 25 \\
Plano de cargos e salánios & 18 \\
Participação nos resultados & 13 \\
Valorização dos colaboradores & 10 \\
Plano de qualidade de vida no trabalho & 4 \\
Incentivo a educação & 4 \\
Vale transporte & 3 \\
Vale alimentação & 3 \\
Plano de saúde & 3 \\
Treinamento & 3 \\
Comissóes & 3 \\
Incentivos motivacionais & 2 \\
Reconhecimento & 2 \\
Plano de previdência social & 2 \\
H válido (de lista) & 1 \\
\hline
\end{tabular}

Quando questionados sobre uma sugestão quanto à forma de atração e retenção de colaboradores, como evidencia a Tabela 10, o requisito que se destacou é o clima organizacional com $25 \%$, seguido de plano de cargos e salários com $18 \%$, participação nos resultados com $13 \%$ e valorização do funcionário com $10 \%$. Vale ressaltar que essa pergunta era aberta o que mostrou que os funcionários prezam pelas necessidades e satisfações pessoais.

Tabela 11 - Correlação de Spearman

\begin{tabular}{rlrrrr}
\hline & & Salário & Tempo & Idade & Escol \\
\hline \multirow{3}{*}{ Salário } & $\mathrm{R}$ & 1,000 & $380^{* *}$ &, $396^{* *}$ &, 105 \\
& Sig &. &, 000 &, 000 & 256 \\
& $\mathrm{~N}$ & 118 & 118 & 118 & 118 \\
\multirow{3}{*}{ Tempo } & $\mathrm{R}$ & $380^{* *}$ & 1,000 & $389^{* *}$ &, 070 \\
& $\mathrm{Sig}$ &, 000 &. &, 000 &, 449 \\
& $\mathrm{~N}$ & 118 & 118 & 118 & 118 \\
Idade & $\mathrm{R}$ & $396^{* *}$ & $389^{* *}$ & 1,000 &, 116 \\
& $\mathrm{Sig}$ &, 000 &, 000 & & 211 \\
& $\mathrm{~N}$ & 118 & 118 & 118 & 118 \\
\hline
\end{tabular}

Nível de Significância: $\left({ }^{* *}\right)$ 1\%; $\left(^{*}\right) 5 \%$

Na Tabela 11 de Correlação de Spearman observa-se elevada associação entre a variável Salário com as variáveis "idade" $(r=0,396 ; p<0,01)$ e "tempo" $(r=0,380 ; p<0,01)$. Denota-se que a ascensão salarial possivelmente converge com Plano de Carreira, que inclui invariavelmente o binômio idade-tempo.

Com o objetivo de diminuir o número de variáveis em análise foi procedida a Análise Fatorial. O modelo apresentou adequação de amostragem (KMO =0,833) e significância no teste de Bartlett $(p<0,001)$. 
Tabela 12 - Variância total explicada

\begin{tabular}{|c|c|c|c|c|c|c|c|c|c|}
\hline \multirow{2}{*}{ Componente } & \multicolumn{3}{|c|}{ Valores próprios iniciais } & \multicolumn{3}{|c|}{$\begin{array}{l}\text { Somas de extração de } \\
\text { carregamentos ao quadrado }\end{array}$} & \multicolumn{3}{|c|}{$\begin{array}{l}\text { Somas rotativas de } \\
\text { carregamentos ao quadrado }\end{array}$} \\
\hline & Total & $\begin{array}{c}\% \text { de } \\
\text { variância }\end{array}$ & $\begin{array}{c}\% \\
\text { cumulativa }\end{array}$ & Total & $\begin{array}{c}\% \text { de } \\
\text { variância }\end{array}$ & $\begin{array}{c}\% \\
\text { cumulativa }\end{array}$ & Total & $\begin{array}{c}\% \text { de } \\
\text { variância }\end{array}$ & $\begin{array}{c}\% \\
\text { cumulativa }\end{array}$ \\
\hline 1 & 7,025 & 39,03 & 39,03 & 7,025 & 39,03 & 39,03 & 4,009 & 22,273 & 22,273 \\
\hline 2 & 2,68 & 14,891 & 53,921 & 2,68 & 14,891 & 53,921 & 3,822 & 21,235 & 43,508 \\
\hline 3 & 1,374 & 7,635 & 61,556 & 1,374 & 7,635 & 61,556 & 2,002 & 11,121 & 54,629 \\
\hline 4 & 1,267 & 7,037 & 68,593 & 1,267 & 7,037 & 68,593 & 1,841 & 10,23 & 64,859 \\
\hline 5 & 1,072 & 5,957 & 74,55 & 1,072 & 5,957 & 74,55 & 1,744 & 9,691 & 74,55 \\
\hline 6 & 0,738 & 4,103 & 78,653 & & & & & & \\
\hline 7 & 0,587 & 3,26 & 81,913 & & & & & & \\
\hline 8 & 0,561 & 3,115 & 85,027 & & & & & & \\
\hline 9 & 0,456 & 2,535 & 87,562 & & & & & & \\
\hline 10 & 0,388 & 2,156 & 89,719 & & & & & & \\
\hline 11 & 0,354 & 1,967 & 91,685 & & & & & & \\
\hline 12 & 0,337 & 1,875 & 93,56 & & & & & & \\
\hline 13 & 0,296 & 1,647 & 95,207 & & & & & & \\
\hline 14 & 0,226 & 1,254 & 96,461 & & & & & & \\
\hline 15 & 0,211 & 1,171 & 97,632 & & & & & & \\
\hline 16 & 0,164 & 0,908 & 98,54 & & & & & & \\
\hline 17 & 0,147 & 0,817 & 99,357 & & & & & & \\
\hline 18 & 0,116 & 0,643 & 100 & & & & & & \\
\hline
\end{tabular}

Método de extração: análise do componente principal.

Na Tabela 12 estão descritos os fatores (variáveis latentes) extraídos na AF. Como foi adotado o critério dos autovalores para seleção das variáveis, cinco fatores foram retidos no modelo, explicando $74,6 \%$ do conjunto das 18 variáveis analisadas.

Tabela 13 - Comunalidades

\begin{tabular}{|c|c|c|c|c|c|}
\hline & Inicial & Extraças. & & Inicial & Extrecäo \\
\hline V_10s & 1 & 0,707 & V_10j & 1 & 0,768 \\
\hline V_10b & 1 & 0,753 & $V_{-}{ }_{10 k}$ & 1 & 0,78 \\
\hline$\nabla_{-} 10 c$ & 1 & 0,755 & V_101 & 1 & 0,743 \\
\hline$V_{-} 10 d$ & 1 & 0,75 & $V_{-} 11 \mathrm{a}$ & 1 & 0,778 \\
\hline$V_{-} 10 e$ & 1 & 0,648 & V_11b & 1 & 0,788 \\
\hline V_lof & 1 & 0,699 & V_lle & 1 & 0,78 \\
\hline V_10g & 1 & 0,609 & $V_{-} 11 d$ & 1 & 0,78 \\
\hline$V_{-} 10 \mathrm{~h}$ & 1 & 0,751 & $V_{-} 11 \mathrm{e}$ & 1 & 0,786 \\
\hline V_10i & 1 & 0,73 & V_11f & 1 & 0,813 \\
\hline
\end{tabular}

Método de extração: análise do componente principal. 
Tabela 13 está relacionada às comunalidades, ou variâncias captadas de cada uma das variáveis envolvidas na análise. Observa-se que, em média, $70 \%$ das variâncias individuais foram absorvidas pelo modelo, conferindo boa qualidade para os construtos.

Na Tabela 14 estão apresentados os cinco fatores extraídos da matriz rotacionada ortogonalmente pelo método varimax com normalização de Kaiser, convergida em sete iterações.

Tabela 14 - Matriz de componente rotativaa

\begin{tabular}{|c|c|c|c|c|c|}
\hline & \multicolumn{5}{|c|}{ Componente } \\
\hline & 1 & 2 & 3 & 4 & 5 \\
\hline V_10h & 0,784 & & & & \\
\hline V_10a & 0,781 & & & & \\
\hline V_10f & 0,773 & & & & \\
\hline V_10i & 0,682 & & & & \\
\hline V_10e & 0,676 & & & & \\
\hline V_10g & 0,62 & & & & \\
\hline V_10k & 0,62 & & & & \\
\hline V_11f & & 0,856 & & & \\
\hline V_11e & & 0,854 & & & \\
\hline V_11d & & 0,84 & & & \\
\hline V_11c & & 0,808 & & & \\
\hline V_11a & & 0,692 & & & \\
\hline V_10d & & & 0,826 & & \\
\hline V_10c & & & 0,791 & & \\
\hline V_10j & & & & 0,814 & \\
\hline V_101 & & & & 0,755 & \\
\hline$V_{-} 11 \mathrm{~b}$ & & & & & 0,746 \\
\hline$V_{-} 10 b$ & & & & & 0,662 \\
\hline
\end{tabular}

Conforme demonstrado na Tabela 14 o primeiro fator agrupado incluiu as seguintes variáveis, ordenadas em ordem decrescente das cargas fatoriais:
a) Plano de Cargos
b) Oportunidade de desenvolvimento
c) Reconhecimento
d) Clima Organizacional
e) Benefícios
f) Novos Desafios
g) Satisfação com o trabalho

Pelo conjunto das variáveis retidas, o fator pode ser descrito como Plano de carreira e Reconhecimento. Este fator traduz elementos relacionados com aspectos associados ao interesse em permanecer na empresa.

O Segundo fator incluiu as seguintes variáveis:

a)Condições de Trabalho 
b) Oportunidade de desenvolvimento

c) Programas de Qualidade de Vida no Trabalho

d) Reconhecimento e Valorização no Trabalho

e) Política de Benefícios e Incentivos

O fator incluiu especificamente variáveis do conjunto das Práticas de Gestão de Pessoas que preza pela qualidade de vida no trabalho e remuneração estratégica.

No terceiro fator agruparam-se as seguintes variáveis:

a) Boa Referência na Sociedade

b) Comprometimento com o Trabalho

O fator resume-se especificamente quanto ao status no trabalho e na sociedade, no requisito a escolher a organização para se trabalhar.

O quarto fator obteve-se seguintes opções:

a) Estabilidade e segurança

b) Flexibilidade no trabalho

Este fator resume-se quanto a Estabilidade e Flexibilidade, como itens que se estacaram momento de escolher entre uma empresa a outra.

Já no quinto fator as variáveis foram à mesma:

a) Salário (escolher a empresa)

b) Salário (permanecer na empresa)

Este fator traduz que o mesmo motivo que faz com que os colaboradores se sintam atraídos a trabalha em uma empresa, é o mesmo quesito que faz com que ele permaneça na organização, e esta variável é o salário.

\section{Considerações Finais}

As empresas estão cada vez mais preocupadas em atrair e manter profissionais em seu corpo funcional, e utilizam cada vez mais estratégias de remunerar seus colaboradores de forma diferenciada.

Mediante os dados coletados através da pesquisa o perfil dos entrevistados são $78,8 \%$ de 18 a 33 anos, $53,4 \%$ são homens e atuam em sua maioria na gerência, 46,6\% são mulheres que atuam de forma homogênea nos níveis de gerencial, técnico e operacional. Qual ao tempo de atuação $51,7 \%$ encontram-se até 3 anos na empresa que trabalham, o que demonstra um grande índice de rotatividade. Quanto a quesito salário $79,66 \%$ dos pesquisados recebem acima de $\mathrm{R} \$ 1.448,01$, pode-se observar na análise dos dados que conforme o tempo de atuação a remuneração aumenta na maioria dos casos.

Ficou demonstrado que quanto ao fator de atração $48 \%$ consideraram o salário como maior fator, referente ao pacote de benefícios, $52 \%$ responderam que este quesito agrega mais valor que o salário, $67 \%$ dos entrevistados afirmaram que em algum momento já se sentiram atraídos pelo salário a mudar de empresa. Com base na análise fatorial conclui-se que os principais motivos atribuídos pelos pesquisados a escolher a empresa em que atuam no momento são: salário, condições de Trabalho, qualidade de vida no trabalho, reconhecimento e valorização, benefícios e incentivos, boa referência e comprometimento. Já os fatores de maior abordagem que os fazem permanecer nelas são: o salário, comprometimento estabilidade e flexibilidade. Conclui-se que o principal motivo que faz com que os colaboradores sejam atraídos e retidos em uma empresa é o fator salário. Segundo Coelho (2012, p. 12) apud Philipchuk e Whitaker 
(1996) "o salário e a segurança no emprego são grandes fatores motivadores".

Acerca das políticas de Gestão de Pessoas os fatores evidenciados foram salários, reconhecimento, benefícios e incentivos. Cabe destacar que quando questionados a importância da valorização e reconhecimento, $97 \%$ atribuíram como fator importante no ambiente de trabalho.

Quanto as sugestões dadas pelos entrevistados na atração e retenção de talentos os fatores optados que obtiveram maior destaque são o clima organizacional, fator ligado a motivação e plano de cargos e salários. O clima organizacional é positivo aos colaboradores quando proporciona satisfação das necessidades básicas e negativo quando oferece insatisfação perante suas necessidades, ou seja, o clima organizacional é influenciado pelo estado motivacional, o que pode-se observar através da pesquisa a grande importância perante a este fator. (MIRANDA, 2009, p.54).

Sabendo que, profissionais talentos fazem de uma organização um diferencial competitivo no mercado, neste artigo analisou-se como os profissionais das organizações são atraídos e retidos a partir da remuneração estratégica na visão de alunos de Pós-Graduação de uma Universidade Pública. Os fatores evidenciados nas análises obtidas como importantes e sempre abordados foram: salário, benefícios, reconhecimento e valorizações.

Respondendo a seguinte problemática: Até que ponto a remuneração estratégica atrai e retém os profissionais nas organizações na visão de Pós-Graduandos? As informações obtidas nessa pesquisa demonstra que o fator salário é considerado o principal quesito na atração e retenção de talento, permitindo concluir que a remuneração estratégica tem grande influência, uma vez que, a remuneração estratégica vem por recompensar os colaboradores por meio de métodos diferenciados em busca sempre de uma melhor valorização na forma de compensá-los pelos serviços prestados.

A remuneração estratégica auxilia os gestores na melhor forma de pagar os colaboradores, juntamente com uma combinação de atributos que vão agregar valor a remuneração, buscando através de esses métodos diferenciados atrair e reter os profissionais talentos.

Que este estudo estimule e sirva como base para novas pesquisas referentes à atração e retenção de talentos nas organizações, buscando uma forma de valorização e reconhecimento adequada para cada cargo desempenhado bem como um clima organizacional que estimule e foque a qualidade de vida do trabalhador. Visto que os quesitos como clima organizacional e plano de cargo e salários estão dentre as sugestões dadas no decorrer da pesquisa, como forma de atrair e reter os profissionais talentos.

\section{Referências}

BERGAMINI, Cecília Whitaker. Motivação nas organizações. São Paulo: Atlas, 1997.

BRASIL. Cadastro Geral de Empregados e Desempregados. Pesquisa Anual: Resultado 2013. Disponível em: http://portal.mte.gov.br/data/files/8A7C816A3DCAE32F013E182E82 E142C0/CAGED\%20Apresenta\%C3\%A7\%C3\%A30\%20Mar\%C3\%A7o_2013\%20(2).pdf. Acesso em: 18 de junho de 2014.

COELHO, Sílvia Diana Almeida. Dissertação de Mestrado em Gestão de Recursos Humanos e Comportamento Organizacional. Coimbra - 2012. Disponível em: http://dspace. ismt.pt/bitstream/123456789/326/1/Silvia\%20Coelhotese_finalLLL.pdf. Acesso em: 18 julho de 2014.

COOPER, D. R. e SCHINDLER, P. S. Métodos de pesquisa em administração. Porto 
Alegre: Bookman, 7 ed., 2003.

DIAS, Bernadete Oliveira S. Viana; BRITO, Silvano Marcelino; BRESSANE, Jacques Murilo. O Sistema de Remuneração das Empresas do Pólo Tecnológico de

Santa Rita do Sapucaí MG. In: XIII Seminários em Administração, 2010. Anais... Disponível em: < http://www.ead.fea.usp.br/semead/13semead/resultado/trabalhosPDF/591. pdf $>$. Acesso em: 25 de fevereiro de 2014.

DUNZER, Gustavo André; MELO, Eliana Medeiros Pereira; MELO, Joyce de Souza Cunha. Desafios de Atração e Retenção de Talentos - Estudo de Caso da Petrobras. In: ENCONTRO NACIONAL DA ASSOCIAÇÃO NACIONAL DOS PROGRAMAS DE PÓS-GRADUAÇÃO EM ADMINISTRAÇÃO, 06. 2008, Anais.... Rio de Janeiro, ANPAD, 2008. Disponível em: <http:// www.anpad.org.br/diversos/trabalhos/EnANPAD/enanpad_2008/GPR/2008_GPRA2012.pdf >. Acesso em: 18 de fevereiro de 2014.

GHENO, Renata; BERLITZ, Jaqueline Berlitz. Remuneração Estratégica e Pacote de Benefícios: um estudo de caso aplicado ao nível operacional de uma multinacional. Revista de Administração da UFSM, Brazilian Journal of Management, Santa Maria, v. 4, n.1, p. 268-287 mai./ago. 2011. Disponível em: <http://cascavel.ufsm.br/revistas/ojs-2.2.2/index.php/reaufsm/ article/view/709 >. Acesso em: 15 de fevereiro de 2014.

GIL, A. C. Como elaborar projetos de pesquisa. São Paulo: Atlas, 4 ed., 2002.

GRESSLER, Lori A. Introdução a Pesquisa: projetos e relatórios. São Paulo: Loyola, 2004.

HAIR, Jr, J.F. Análise Multivariada. R.E. Anderson, RL. Tatham e WC, Black; Trad. Adonai Schlup Sant'Anna e Anselmo. Chaves Neto - 5 ed. - Porto Alegre: Bookman, 2005.

JUNIOR, Ilton Curty Leal; SILVA, Anne Jeferson C. da. A implementação do sistema de benefícios nas organizações como fator de desenvolvimento empresarial consistente um panorama da região sul fluminense. In: II SIMPOSIO DE EXCELENCIA EM GESTAO E TECNOLOGIA: ASSOCIACAO EDUCACIONAL DOM BOSCO, 2006, Anais... Rio de Janeiro, SEDeT, 2006. Disponível em: <http://www.aedb.br/seget/artigos06/554_Beneficios\%20 Espontaneos\%20Seget.pdf>.

Acesso em: 08 de março de 2014.

JUNIOR, Nelson da Rocha França. Retenção de Talentos: Consideração de aspectos determinantes na empresa Volvo do Brasil Veículos S/A. 2010. Dissertação (Mestrado) Universidade Tecnológica Federal do Paraná, Programa de Pós-graduação em Engenharia de Produção, Ponta Grossa. Disponível em: < http://www.pg.utfpr.edu.br/dirppg/ppgep/ dissertacoes/arquivos/160/Dissertacao.pdf > . Acesso em: 05 de março de 2014.

MIRANDA, Cely. O desafio em manter funcionários motivados: Os Fatores Motivacionais para o Trabalho. 2009. Monografia - Escola Superior Aberta do Brasil, Vila Velha. Disponível em: http://www.esab.edu.br/arquivos/monografias/cely-miranda.pdf . Acesso em: 22 março 2014.

MARQUART, André; LUNKES, Rogério João; ROSA, Fabrícia Silva. Um estudo sobre práticas de remuneração estratégica nas maiores empresas de Santa Catarina. Gestão e Sociedade, v. 6, n. 13, p. 4-25, jan/abril. 2012. Disponível em: <http://www.gestaoesociedade. org/gestaoesociedade/article/view/1289>. Acesso em: 05 de fevereiro de 2014.

MARTINS, Sérgio Silveira; VERIANO, Carlos Evangelista. A remuneração flexível como componente da gestão de salários. Revista de Administração de Empresas, vol. 44, p. 2233, Ed. Especial, 2004. Disponível em: http://rae.fgv.br/sites/rae.fgv.br/files/artigos/10.1590_ S0034-75902004000000003.pdf. Acesso em: 18 fevereiro de 2014.

MELLO, Daniel Andere; SANTOS, Tatiani Silva. Variáveis de Retenção no Setor 
Bancário. In: XIII Seminários em Administração, 2012. São Paulo. Anais... Disponível em: $\quad$ <ttp://www.progep.org.br/MelhoresEmpresas/InfoDocs/Vari\%C3\%A1veis\%20de\%20 Reten $\%$ C3\%A7\%C3\%A30\%20no\%20Setor\%20Banc\%C3\%A1rio.pdf?Mobile=1 >. Acesso em: 02 de março de 2014.

NASCIMENTO, L. et al. A importância da atração e retenção englobando a gestão de pessoas: uma pesquisa bibliográfica. Múltiplo Saber. v. 16, n 1, abril/ junho. 2011. Disponível em: < http://www.inesul.edu.br/revista/arquivos/arq-idvol_17_1339724660.pdf . Acesso em: 18 de março de 2014.

PASSOS, Francisca Elisandra Fortaleza. A influencia dos benefícios oferecidos pelo Banco do Brasil na satisfação e motivação dos colaboradores: Estudo de caso na agência de Fronteirãs/PI. 2012. Monografia - Universidade Federal do Piauí, Administração.

Disponível em: <http:/www.ufpi.br/subsiteFiles/admpicos/arquivos/files/ MONOGRAFIA\%20FRANCISCA\%20ELISANDRA\%20FORTALEZA\%20PASSOS\%202012. pdf. Acesso em: 08 de março de 2014.

SILVA, Elson Magno da. Os efeitos da liderança na retenção de talentos um estudo sobre comprometimento e rotatividade numa indústria petroquímica. Dissertação (Mestrado) - Faculdade de Economia e Finanças, Pós-graduação e Pesquisa em Administração e Economia. 2006. Disponível em: <http://tupi.fisica.ufmg.br/ michel/docs/ Artigos_e_textos/Lideranca/004\%20-\%200s\%20efeitos\%20da\%20lideran\%E7a\%20na\%20 reten\%E7\%E3o\%20de\%20talentos.pdf >. Acesso em 10 de março de 2014.

TRINDADE, C. et al. Até aonde os benefícios influenciam a permanência do funcionário na empresa? Disponível em: < https://www.google.com.br/url?sa=t\&rct=j\&q=\&esrc=s\&sour $c e=w e b \& c d=2 \& c a d=r j a \& u a c t=8 \& v e d=0 C D M Q F j A B \& u r l=h t t p \% 3 A \% 2 F \% 2 F w w w . g p c o n . c o m$. br\%2Fsite\%2Fdownload_file.php\%3Farquivo\%3D20110521224314000000-ate-onde-osbeneficios-influenciam____._edicao_2010.pdf\&ei=StEyU-jIF4fSkQeK44GIAQ\&usg=AFQjCN HIJQaSB1MQL3u-8lj9Pt-sH_7IrQ >. Acesso em 02 de fevereiro de 2014.

WANGA, Gordon; SINGHB, Parbudyal. The evolution of CEO compensation over the organizational life cycle: A contingency explanation. Human Resource Management Review, rev. 24, p. 144-159. 2014.

WOOD JR., T.; PICARELLI FILHO, V. Remuneração estratégica: a nova vantagem competitiva. São Paulo: Atlas, 2004.

ZAMBRANO, Lidia García; Merino, José Domingo García; Castellanos, Arturo Rodríguez. Impacto de la inversión em capital humano sobre el valor empresarial. Academia, Revista Latinoamericana de Adminstracíon, 51, 2012, p.15-26. Disponível

em: <http://revistaacademia.uniandes.edu.co/index.php/Cladea/article/view/539/627 >. Acesso em 28 de fevereiro de 2014.

ZHANGA, Yixiang; WANGA, Zhaohua, ZHOUC, Guanghui Zhouc. Determinants of employee electricity saving: the role of social benefits, personal benefits and organizational electricity saving climate. Journal of Cleaner Production, v. 66, p. 280-287. 2014. 